\title{
Strategi Pengembangan Usahatani Padi Organik di Kecamatan Sumber Jambe Kabupaten Jember
}

\section{Development Strategy of Organic Rice Farming in Sumber Jambe Sub-District Jember Regency}

\author{
Dyah Kusuma Wardani $^{\# 1}$, Linda Ekadewi Widyatami ${ }^{2}$ \\ \#Jurusan Manajemen Agribisnis, Politeknik Negeri Jember, \\ Jl. Mastrip PO BOX 164 Jember \\ E-mail : dyahwardaniepolije.ac.id
}

\begin{abstract}
The purpose of this research was to analyze strategy of organic rice farming in Sumber Jambe Sub-District, Jember Regency. A purposive sampling method was carried out during this research and the members of "Tani Jaya 2" Farmer Group, Rowosari Village, Sumber Jambe Sub-district, which runs organic rice farming was the sample of it. The analysis method used in this research was SWOT Analysis (Strenght, Weakness, Opportunity, Threat). Matrics score of IFE (Internal Factor Evaluation) is 2.566 dan EFE (External Factor Evaluation) is 3.032. Score position of IE (Internal External) in second quadrant to growth and build. SWOT analysis produced four alternative strategies are production seed development to increase the quality of organic rice, increasing storage capacity to fulfill the potential market, increasing production quantity of organic rice in Jember Regency, Monitoring and evaluating the S.O.P of organic rice farming.
\end{abstract}

Keywords : Development Strategy, Organic Rice, SWOT Analysis, Jember

\section{Pendahuluan}

Pembangunan berkelanjutan pada sektor pertanian diimplementasikan pada pertanian berkelanjutan. Pertanian organik sejalan dengan pembangunan pertanian yang berkelanjutan. Pertanian Organik yaitu suatu cara budidaya dan pengusahaan pertanian dengan mengandalkan input dan sarana produksi bahan organik tanpa menggunakan kimia sintesis, rekayasa Genetically Modified Oganism serta segala input luar yang menurunkan kualitas lahan [1].

Mayrowani[2] menyatakan bahwa peningkatan pendapatan domestik bruto, ekspor, penciptaan lapangan kerja, penanggulangan kemiskinan dan peningkatan kesejahteraan masyarakat dapat mendorong kontribusi sektor pertanian terhadap perekonomian nasional melalui sistem perdagangan internasional "Pengembangan Pertanian Organik di Indonesia". Program pengembangan pertanian organik di Indonesia membantu mewujudkan pertanian tangguh, berdaya saing berkelanjutan dan berwawasan lingkungan.

Potensi pengembangan produk lokal dalam upaya peningkatan daya saing produk lokal dan peningkatan ketahanan pangan serta berorientasi pada pembangunan pertanian berkelanjutan yang dapat dikembangkan di Kabupaten Jember adalah usahatani padi organik di Desa Rowosari Kecamatan Sumberjambe. Pertanian padi organik di Kabupaten Jember pertama kali dikembangkan di Desa Rowosari Kecamatan Sumberjambe pada Tahun 2012, oleh Kelompok Tani “Tani Jaya 2". Berdasarkan latar belakang tersebut, maka peneliti melakukan penelitian dengan Judul "Strategi Pengembagan 
Usahatani Padi Organik di Kecamatan Sumberjambe Kabupaten Jember".

\section{Metode Penelitian}

Penelitian ini dilakukan di Desa Rowosari Kecamatan Sumberjambe Kabupaten Jember, yaitu di Kelompok Tani "Tani Jaya 2". Penentuan daerah penelitian ini ditentukan berdasarkan metode yang disengaja (purposive method). Dasar penentuan pemilihan lokasi penelitian yaitu Desa Rowosari khususnya Kelompok Tani "Tani Jaya 2" merupakan pelopor dan satu-satunya daerah atau kelompok tani di Kabupaten Jember yang menjalankan usahatani padi organik dan telah mendapatkan sertifikasi organik dari lembaga sertifikasi organik LeSOS.

Metode pengumpulan data pada penelitian ini adalah a) data primer yaitu data yang diperoleh langsung dari responden dengan metode wawancara berdasarkan daftar pertanyaan pada kuisioner. b)data sekunder yaitu data yang sudah terdapat dalam pustaka atau data resmi yang dikumpulkan oleh lembaga/instansi seperti Kelompok Tani, Dinas Pertanian, serta instansi lainnya yang berkaitan dengan penelitian ini.

Metode pengambilan sampel penelitian untuk menganalisis pengembangan usahatani padi organik dilakukan untuk menganalisis strategi pengembangan usahatani padi organik yaitu metode expert system (metode pemilihan pakar). Metode analisis yang digunakan untuk menganalisis Strategi Pengembangan Usahatani Padi Organik adalah Analisis SWOT. [3] Fahmi (2016) menjelaskan tahapan dalam melakukan Analisis SWOT yaitu: a) Menyusun dan menentukan faktor-faktor strategis Eksternal dan Internal suatu usaha. b) Menganalisis dan menentukan keputusan strategis dengan pendekatan Matriks SWOT.

Perencanaan strategis harus menganalisis faktor strategis yang sesuai dengan kondisi perusahaan terkini. Tahap terakhir yaitu tahap keputusan, berisi strategi prioritas yang dihasilkan melalui pengolahan alternatif-alternatif strategi yang dihasilkan pada tahap sebelumnya [4] David, 2012.

\section{HASIL DAN PEMBAHASAN}

Perumusan strategi dilakukan dengan menyusun faktor internal dan eksternal dari usahatani padi organik di Desa Rowosari Kecamatan Sumberjambe Kabupaten Jember dapat dijelaskan sebagai berikut.

A. Identifikasi Faktor Internal Usahatani Padi Organik di Kecamatan Sumberjambe Kabupaten Jember

Faktor internal dikatakan sebagai kekuatan jika terdapat keunggulan kompetitif bagi perusahaan atau usahanya dibandingkan usaha lain dalam suatu bidang usaha. Suatu faktor internal dikatakan kelemahan jika terdapat hal yang tidak diterapkan dengan baik oleh suatu bidang usaha. Faktor-faktor kekuatan dan kelemahan dari usahatani padi organik di Desa Rowosari Kecamatan Sumberjambe ditunjukkan pada Tabel 1.

Evaluasi faktor internal dilakukan dengan menghitung rata-rata tertimbang masing-masing faktor kunci internal, kemudian disusun dalam sebuah matriks evaluasi masing-masing faktor. Pada matriks evaluasi tersebut, faktor kekuatan dan kelemahan ditambahkan dengan menggunakan metode pembobotan paired comparison. Hasil analisis matriks IFE menunjukkan faktor kekuatan utama kelompok tani padi organik di Kecamatan Sumber Jambe Kabupaten Jember yaitu Produk Beras Organik sudah bersertifikat dengan nilai skor 0.302. Kondisi ini menunjukkan bahwa memiliki standart sertifikasi yang telah dikeluarkan oleh LeSOS merupakan kunci agar produk dapat diterima oleh masyarakat. Faktor kekuatan tersebut didukung dengan Standar Operasional Prosedur (SOP) yang baku dan memiliki tim penjaminan mutu internal (Internal Control System/ICS) sehingga dapat menghasilkan padi organik yang berkualitas. Matriks IFE juga menunjukkan hasil analisis faktor kelemahan yaitu tempat atau gudang penyimpanan produksi yang terbatas dengan nilai skor 0.116 . Gudang penyimpanan produksi yang terbatas pada kelompok tani padi organik di Desa Rowosari Kecamatan Sumber Jambe Kabupaten Jember menyebabkan jumlah produksi yang dihasilkan masih belum mampu memenuhi permintaan pasar.

\section{B. Identifikasi Faktor Eksternal Usahatani Padi Organik di Kecamatan Sumberjambe Kabupaten Jember}

Evaluasi faktor eksternal dilakukan dengan menghitung rata-rata tertimbang masing-masing faktor kunci eksternal yang selanjutnya disusun dalam sebuah matriks evaluasi masing-masing faktor. Matriks evaluasi tersebut, faktor peluang dan ancaman ditambahkan dengan menggunakan metode pembobotan paired comparison. Matriks External Factor Evaluation (EFE) digunakan untuk melihat keadaan eksternal perusahaan atau usaha. Hasil analisis EFE dapat dilihat pada Tabel 2.

Hasil analisis matriks EFE, faktor peluang utama yaitu potensi pasar yang masih luas dengan nilai skor sebesar 0.391. Peluang utama tersebut didukung dengan kondisi masyarakat Indonesia dalam menempatkan nasi sebagai kebutuhan makanan pokok yang utama. Terutama konsumsi beras organik di Jember masih rendah. Indonesia juga diberi anugerah kondisi alam yang mendukung yaitu melimpahnya ketersediaan air dan tanah yang subur.

Faktor ancaman utama yang dihadapi usahatani padi organik di Desa Rowosari Kecamatan Sumber Jambe yaitu kenaikan tarif dasar listrik yang berpengaruh terhadap biaya produksi dengan skor sebesar 0.383. Kelompok tani padi organik di Kecamatan Sumber Jambe Kabupaten Jember 
Dyah Kusuma Wardani, Linda Ekadewi Widyatami, Analisis Daya Saing Pengembangan Usahatani Padi Organik di Kecamatan Sumber Jambe Kabupaten Jember

menggunakan teknologi modern yang menggunakan sumber listrik dalam proses pengolahan beras organik, sehingga kenaikan tarif dasar listrik menjadi hal yang dikhawatirkan oleh kelompok tani. Kenaikan tarif daftar listrik dapat meningkatkan biaya produksi proses penggilingan padi, khususnya biaya listrik, dan kenaikan tarif dasar listrik juga dapat menjadi pemicu naiknya harga sembako yang akan berimbas langsung pada kenaikan upah tenaga kerja. Hasil analisis juga menghasilkan total skor tertimbang sebesar 3.032. Hal ini menunjukkan bahwa respon kelompok tani terhadap faktor eksternal tinggi. Hasil ini memperlihatkan bahwa usaha tani padi organik di Kecamatan Sumber Jambe Kabupaten Jember telah mampu memaksimalkan peluang dan menghindari ancaman.

Tabel 1. Hasil analisis internal factor Evaluation pada Usahatani Padi Organik di Desa Rowosari Kecamatan SUMBERJAMBE KABUPATEN JEMBER

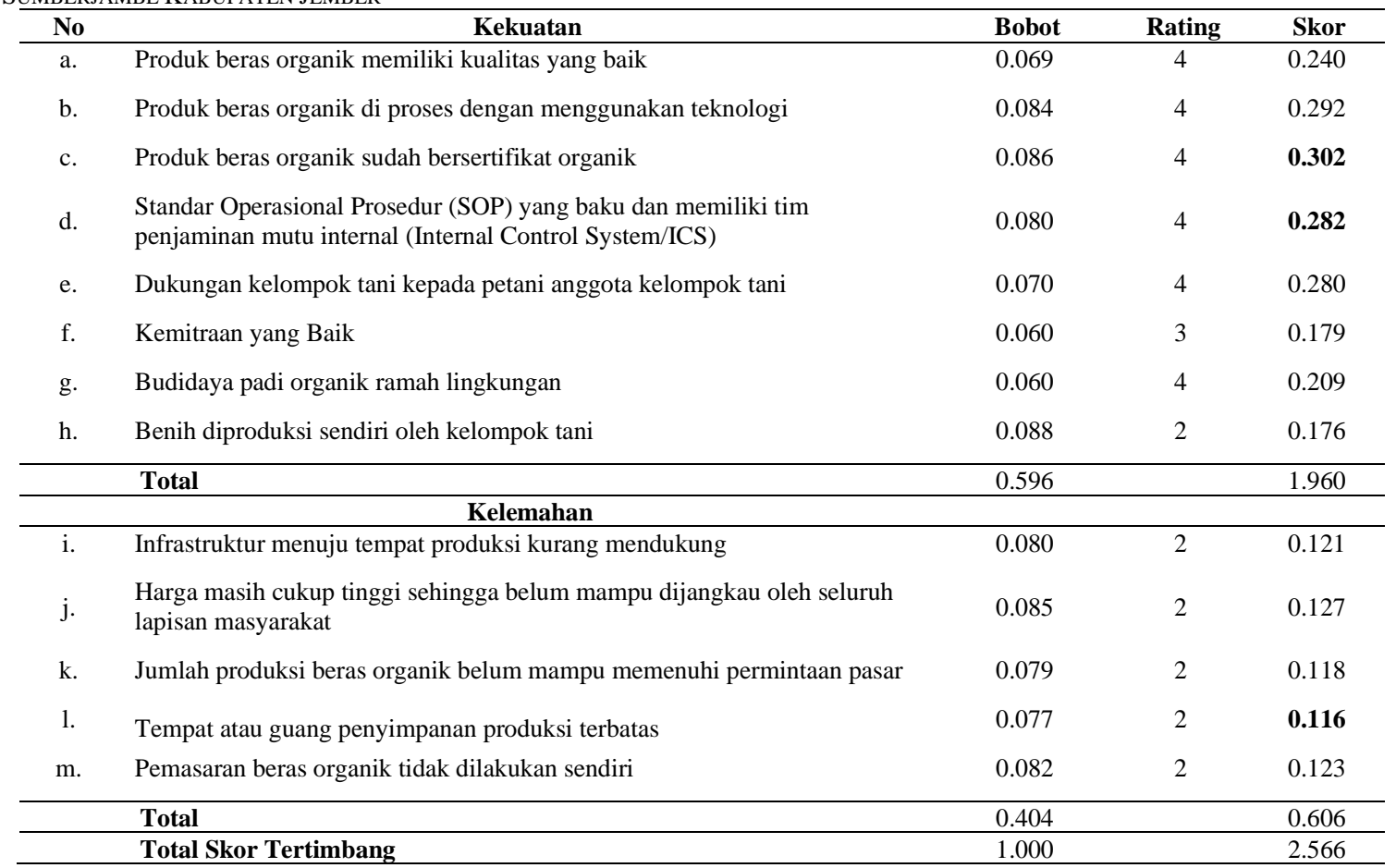

Sumber: Data Primer Diolah Tahun 2020

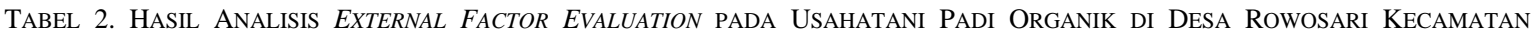
SUMBERJAMBE KABUPATEN JEMBER

\begin{tabular}{|c|c|c|c|c|}
\hline No & Peluang & Bobot & Rating & Skor \\
\hline a. & Kebijakan pemerintah yang mendukung pertanian padi organik & 0.109 & 3 & 0.271 \\
\hline $\mathrm{b}$ & Konsumsi beras organik di Jember masih rendah & 0.109 & 4 & 0.380 \\
\hline c. & Potensi pasar masih luas & 0.112 & 4 & 0.391 \\
\hline $\mathrm{d}$. & Kondisi alam yang mendukung & 0.080 & 3 & 0.240 \\
\hline & Total & 0.409 & & 1.282 \\
\hline \multicolumn{5}{|c|}{ Ancaman } \\
\hline e. & Upah pekerja yang semakin meningkat & 0.099 & 4 & 0.347 \\
\hline f. & Produk beras organik impor & 0.102 & 3 & 0.307 \\
\hline g. & Perusaahaan pesaing dari sekitar kota Jember & 0,115 & 3 & 0.345 \\
\hline h. & Hama dan Penyakit Tanaman Padi & 0.147 & 3 & 0.367 \\
\hline i. & Kenaikan tarif dasar listrik yang berpengaruh terhadap biaya produksi & 0.128 & 3 & 0.383 \\
\hline & Total & 0.591 & & 1.750 \\
\hline & Total Skor Tertimbang & 1.000 & & $\mathbf{3 . 0 3 2}$ \\
\hline
\end{tabular}

Sumber: Data Primer Diolah Tahun 2020 
C. Matriks Internal-Eksternal (Matriks IE) dan Mastriks Analisis SWOT pada Usahatani Padi Organik di Kecamatan Sumberjambe Kabupaten Jember

Kelompok tani memerlukan strategi pengembangan usahatani padi organik di Desa Rowosari Kecamatan Sumberjambe Kabupaten Jember. Langkah tersebut dilakukan dengan melihat letak skor pada kuadran dalam matriks internal dan eksternal. Matriks IFE dan EFE yang telah diberi bobot dan peringkat serta memiliki skor rata-rata tertimbang, kemudian digabung dalam matriks internal dan eksternal yang menunjukkan keberhasilan strategi yang dijalankan oleh usahatani padi organik di Kecamatan Sumberjambe Kabupaten Jember dalam mengembangkan usahatani padi organik yang dilakukan. Hasil analisis dengan menggunakan IFE dan EFE masing-masing diperoleh skor $\mathrm{IFE}=2.566$ dan $\mathrm{EFE}=3.032$. Skor ini dimasukkan ke dalam Analisis Internal Eksternal (IE) yang menempatkan posisi usahatani padi organik berada pada kuadran II (Growth dan Build) artinya strategi yang dapat dilakukan adalah dengan menerapkan intensive strategy dan integration strategy, serta dapat dilakukan merger dan strategic alliance. Intensive strategy dapat dilakukan dengan melakukan penetrasi pasar, pengembangan pasar, dan pengembangan produk. Integration strategy dapat dilakukan dengan melakukan integrasi ke belakang, integrasi ke depan dan integrasi horizontal. Posisi usahatani padi organik di Desa Rowosari Kecamatan Sumberjambe berdasarkan matriks IE dapat dilihat pada Gambar 1.

Berdasarkan hasil analisis matriks IFE dan EFE kemudian dapat dipetakan alternatif strategi pengembangan usahatani padi organik yang sesuai, dengan memadukan setiap faktor yaitu faktor kekuatan (streghts), kelemahan (weaknesses), peluang (opportunities), dan ancaman (threaths). Hasil analisis matriks analisis SWOT pada usahatani padi organik di Desa Rowosari Kecamatan Sumberjambe Kabupaten Jember dapat dilihat pada Gambar 2.

Total Nilai IFE yang dibobot $(2,566)$

\begin{tabular}{|c|c|c|}
\hline $\begin{array}{l}\text { uat } \\
-4,00\end{array}$ & $\begin{array}{c}\text { Rata-rata } \\
2,00-2,99\end{array}$ & $\begin{array}{c}\text { Lemah } \\
0,00-1,99 \\
\end{array}$ \\
\hline I & $\begin{array}{c}\text { II } \\
\text { (Growth and } \\
\text { Build) }\end{array}$ & III \\
\hline V & V & VI \\
\hline III & VIII & IX \\
\hline
\end{tabular}


Dyah Kusuma Wardani, Linda Ekadewi Widyatami, Analisis Daya Saing Pengembangan Usahatani Padi Organik di Kecamatan Sumber Jambe Kabupaten Jember

\section{STRENGHTS}

\section{WEAKNESSES}

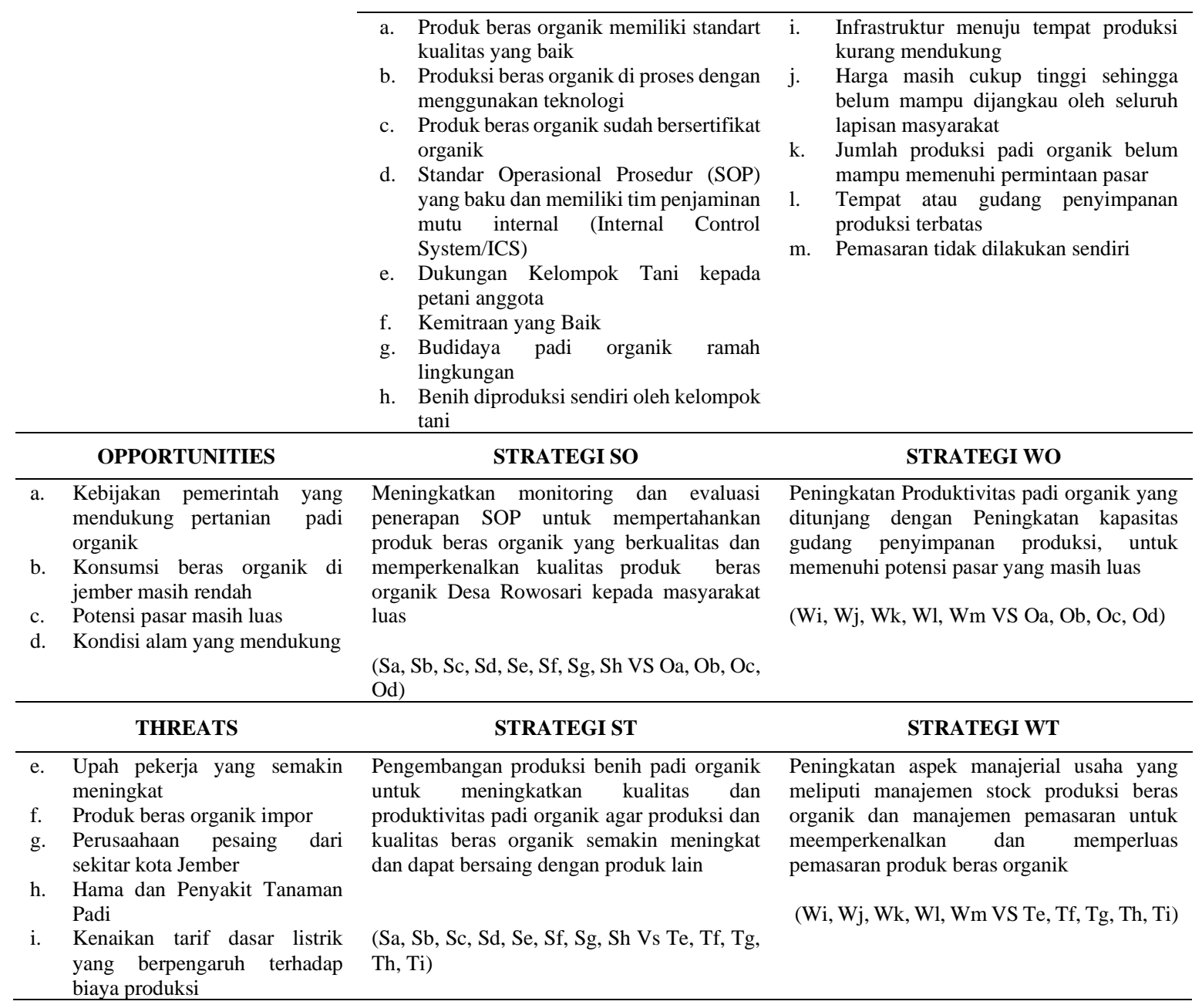

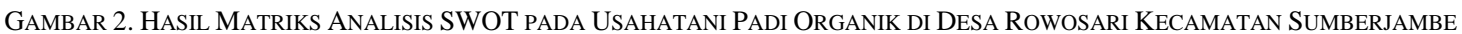
KABUPATEN JEMBER

\section{KESIMPULAN}

Berdasarkan matriks Analisis SWOT maka diperoleh alternatif strategi pengembangan usahatani padi organik di Desa Rowosari yaitu: (1) Meningkatkan monitoring dan evaluasi penerapan SOP untuk mempertahankan produk beras organik yang berkualitas dan memperkenalkan kualitas produk beras organik Desa Rowosari kepada masyarakat luas; (2) Pengembangan produksi benih padi organik untuk meningkatkan kualitas dan produktivitas padi organik agar semakin meningkat dan dapat bersaing dengan produk lain; (3) Peningkatan Produktivitas padi organik yang ditunjang dengan peningkatan kapasitas gudang penyimpanan produksi, untuk memenuhi potensi pasar yang masih luas; (4) Peningkatan aspek manajerial usaha yang meliputi manajemen stock produksi beras organik dan manajemen pemasaran untuk memperkenalkan dan memperluas pemasaran produk beras organik.

\section{DAFTAR PUSTAKA}

[1] Bargumono. 2016. Pertanian Organik: Solusi Alternatif Pertanian. Yogyakarta: Global Pustakan Utama.

[2] Mayrowani, Henny. 2012. "Pengembangan Pertanian Organik di Indonesia". Dalam Forum Penelitian Agro Ekonomi. Vol. 30. No. 2. Hal 91108. Bogor: Pusat Sosial Ekonomi dan Kebijakan Pertanian.

[3] Fahmi, Irham. 2016. Teori dan Teknik Pengambilan Keputusan Kualitatif dan Kuantitatif. Depok: PT. Rajagrafindo Persada.

[4] David, F.R. 2012. Manajemen Strategis: Konsep. Jakarta: Salemba Empat. 